\title{
Concurrent threats and disasters: modeling and managing risk and resilience
}

\author{
Zachary A. Collier ${ }^{1}$. James H. Lambert ${ }^{2} \cdot$ Igor Linkov $^{3}$
}

Published online: 3 September 2020

○) Springer Science+Business Media, LLC, part of Springer Nature 2020

The global COVID-19 pandemic has prompted policy makers to reassess the operations and management of society's critical functions, including infrastructure, health care services, supply chains, and emergency response. With COVID-19 as a backdrop, planning and response activities must continue to occur to be able to effectively deploy resources for other disasters which may unfold simultaneously. For example, the concurrence of severe hurricanes and the global pandemic presents unique challenges for disaster management.

The presence of concurrent threats requires an approach that considers both risk and resilience. While risk analysis answers the questions "what can go wrong?", "how likely is it?", and "what are the consequences?", risk analysis can only yield benefits in situations where one can reasonably predict the likelihood and consequences of an adverse event. In many emerging threat environments, or where there are multiple threats, it becomes difficult to parameterize the models necessary to conduct a reliable risk assessment. Resilience take a different and complementary approach, by considering how a system can plan/prepare, absorb, recover, and adapt to disruptions in such a way as to minimize the effect to critical system functions. Taking a resilience approach does not seek to identify every possible threat, but instead allocates resources to designing and protecting the system in such a way as to be able to bounce back quickly from disruptions. Risk and Resilience have been central themes of this Journal, including the topic of multiple Special Issues, including Volume 35, Issue 2 (Linkov

Igor Linkov

Igor.Linkov@usace.army.mil

Zachary A. Collier

zachary@collierresearchsystems.com

1 Collier Research Systems, Barboursville, VA, USA

2 University of Virginia, Charlottesville, VA, USA

3 US Army Engineer Research \& Development Center, Concord, MA, USA et al. 2015) and Volume 38, Issue 3 (Kete et al. 2018). Risk and resilience have been discussed in other books and publications as well (see Linkov and Trump 2019 for review).

COVID-19 has unearthed some of the same issues discussed in the disaster assessment and management literature. While the previous special issue was focused on COVID19, this issue of Environment Systems \& Decisions presents a collection of papers which focus on various aspects of risk and resilience related to disaster management. These disasters include natural (e.g., severe weather events) and manmade (e.g., cyber threats, pipeline explosions) examples. Moreover, resilience is examined from the perspective of protecting against these discrete events, as well as long-term trends, such as climate change. These papers echo patterns from disaster management literature that can be useful in understanding and managing COVID-19.

COVID modeling presented a clear challenge and attracted media attention. In March 2020, the modeling forecasts (providing essential information on disease prevalence that society demanded) changed by orders of magnitude literally within the timeframe of a couple of weeks. "Can you trust a model whose output keeps changing?" ask Naeini et al. (2020). Of course the answer is "yes." Models could and should be trusted, but results should be appropriately communicated and understood. Model uncertainty is often hidden under multiple assumptions and is not communicated properly. For example, Linkov and Burmistrov $(2003,2005)$ observed that post-crises model uncertainty can result in orders of magnitude difference in predicting simple endpoints. This is what can be expected from models applied to new conditions without historical calibration data.

Following the general theme of resilience, Bellini et al. (2020) describe the concept of resilience in general, and apply resilience principles to critical infrastructure systems supporting urban transportation. They describe the processes involved in establishing resilience management guidelines, developing resilience tools, and defining performance indicators, all of which can be applied to a number 
of other contexts. Herrera and Kopainsky (2020) describe a methodology for involving stakeholders in a participatory assessment of resilience. The authors describe how system dynamics modeling can be used to design system interventions which build resilience into the system and account for stakeholder needs and requirements.

The next group of papers deals with the planning and preparation necessary for risk and resilience, prior to a disruption. For example, McIntosh and Becker (2020) develop a decision model which derives weights for sensitivity, exposure, and adaptive capacity indicators for maritime ports subject to disruptions from severe weather and climate change. These indicators were used to rank ports based on their vulnerability, which is useful for allocating resilience-enhancing resources to ensure continuity of port operations. An important component of risk management and resilience is the ability to collect relevant data, and Caruzzo et al. (2020) describe a decision model for supplier selection of weather radars. This has direct implications for disaster preparedness and response to severe weather events. Another important concern related to severe weather and climate change is flood risk management. Sandri et al. (2020) describe and compare governance frameworks applied to reducing accident hazards in natural gas pipelines. Proper governance and planning can contribute to the reduction in pipeline accidents and therefore reduce impacts to human lives, environmental degradation, and economic losses.

The final group of papers focuses on the response to disasters once they have occurred, and how the risks can be mitigated, as well as how society can absorb, recover, and adapt to disruptions. Ha (2020) compares the disaster management practices from developing and developed nations and provides recommendations about how disaster management can become more inclusive to involve stakeholders and to consider factors such as risks, politics, resources, and time. Maslen et al. (2020) explore the role of hazard and incident reporting in preventing health, aviation, and constructions disasters. They describe survey results which provide insights into how legal liability concerns impact hazard and incident reporting, and thus disaster prevention. Assmuth et al. (2020) describe approaches taken in Finland related to minimizing the impacts associated with flooding, especially related to the potential health impacts associated with flood events. Renwick (2020) applies a decision model to the topic of food security, which is an essential societal function which can be disrupted by disasters. Ensuring a stable food supply after a disaster is a multi-stakeholder endeavor involving government, farmers, local businesses, and international suppliers.

Together with the previous Special Issue on "Systemic Risk, Resilience, and COVID-19" (Trump and Linkov 2020), this issue of Environment Systems and Decisions provides a foundation for dealing with systemic crises like COVID-19. The principles and methods of risk and resilience represent fruitful paradigms for planners and policy makers for ensuring that critical social, economic, and environmental systems are able to withstand and bounce back from wide array of threats - not only the current known threats of COVID-19, climate change, and global instability, but also the unforeseen threats of the future.

\section{References}

Assmuth T, Dubrovin T, Lyytimäki J (2020) Human health in systemic adaptation to climate change: insights from flood risk management in a river basin. Environ Syst Decis. https://doi.org/10.1007/s1066 9-019-09751-1

Bellini E, Gaitanidou E, Bekiaris E, Ferreira P (2020) The RESOLUTE project's European Resilience Management Guidelines for Critical Infrastructure: development, operationalisation and testing for the urban transport system. Environ Syst Decis. https://doi.org/10.1007/ s10669-020-09765-0

Caruzzo A, Rodrigues Blanco CM, Joe P (2020) Developing a multiattribute decision aid model for selection of a weather radar supplier. Environ Syst Decis. https://doi.org/10.1007/s10669-020-09770-3

Ha KM (2020) Disaster management: from a one-sided approach to an inclusive system. Environ Syst Decis. https://doi.org/10.1007/s1066 9-019-09755-x

Herrera H, Kopainsky B (2020) Using system dynamics to support a participatory assessment of resilience. Environ Syst Decis. https:// doi.org/10.1007/s10669-020-09760-5

Kete N, Punzo G, Linkov I (2018) Enhancing resilience within and between critical infrastructure systems. Environ Syst Decis 38(3):257-277

Linkov I, Burmistrov D (2003) Model uncertainty and choices made by modelers: lessons learned from the International Atomic Energy Agency Model Intercomparisons. Risk Anal 23:1335-1346

Linkov I, Burmistrov D (2005) Sources of uncertainty in model predictions: lessons learned from the IAEA Forest and Fruit Working Group Model Intercomparisons. J Environ Radioact 84:297-314

Linkov I, Trump BD (2019) The science and practice of resilience. Springer, Cham

Linkov I, Larkin S, Lambert JH (2015) Concepts and approaches to resilience in a variety of governance and regulatory domains. Environ Syst Decis 35(2): 183-184

Maslen S, Hayes J, Wong J, Scott-Young C (2020) Witch hunts and scapegoats: an investigation into the impact of personal liability concerns on engineers' reporting of risks. Environ Syst Decis. https://doi. org/10.1007/s10669-020-09757-0

McIntosh RD, Becker A (2020) Applying MCDA to weight indicators of seaport vulnerability to climate and extreme weather impacts for U.S. North Atlantic ports. Environ Syst Decis. https://doi. org/10.1007/s10669-020-09767-y

Naeini ME, Leibowicz BD, Bickel JE (2020) Can you trust a model whose output keeps changing? Interpreting changes in the social cost of carbon produced by the DICE model. Environ Syst Decis. https://doi.org/10.1007/s10669-020-09783-y

Renwick S (2020) Ranking of scenarios, actors and goals of food security: motivation for information seeking by food security decision makers. Environ Syst Decis. https://doi.org/10.1007/s10669-020-09756 $-1$

Sandri O, Hayes J, Holdsworth S (2020) Regulating urban development around major accident hazard pipelines: a systems comparison of governance frameworks in Australia and the UK. Environ Syst Decis. https://doi.org/10.1007/s10669-020-09785-w

Trump BD, Linkov I (2020) Risk and resilience in the time of the COVID-19 crisis. Environ Syst Decis 40(2):171-173 